\title{
Recent advances in ecological stoichiometry: insights for population and community ecology
}

\author{
S. Jannicke Moe, Robert S. Stelzer, M. Rebecca Forman, W. Stanley Harpole, Tanguy Daufresne and \\ Takehito Yoshida
}

Moe, S. J., Stelzer, R. S., Forman, M. R., Harpole, W. S., Daufresne, T. and Yoshida, T. 2005. Recent advances in ecological stoichiometry: insights for population and community ecology. - Oikos 109: 29-39.

\begin{abstract}
Conventional theories of population and community dynamics are based on a single currency such as number of individuals, biomass, carbon or energy. However, organisms are constructed of multiple elements and often require them (in particular carbon, phosphorus and nitrogen) in different ratios than provided by their resources; this mismatch may constrain the net transfer of energy and elements through trophic levels. Ecological stoichiometry, the study of the balance of elements in ecological processes, offers a framework for exploring ecological effects of such constraints. We review recent theoretical and empirical studies that have considered how stoichiometry may affect population and community dynamics. These studies show that stoichiometric constraints can affect several properties of populations (e.g. stability, oscillations, consumer extinction) and communities (e.g. coexistence of competitors, competitive interactions between different guilds). We highlight gaps in general knowledge and focus on areas of population and community ecology where incorporation of stoichiometric constraints may be particularly fruitful, such as studies of demographic bottlenecks, spatial processes, and multi-species interactions. Finally, we suggest promising directions for new research by recommending potential study systems (terrestrial insects, detritivory-based webs, soil communities) to improve our understanding of populations and communities. Our conclusion is that a better integration of stoichiometric principles and other theoretical approaches in ecology may allow for a richer understanding of both population and community structure and dynamics.
\end{abstract}

S. J. Moe, Norwegian Inst. for Water Research, NO-0411 Oslo, Norway (jannicke. moe@niva.no) and Centre for Ecological and Evolutionary Synthesis (CEES), Univ. of Oslo, NO-0316 Oslo, Norway. - R. S. Stelzer, Dept of Biology and Microbiology, Univ. of Wisconsin Oshkosh, Oshkosh, WI 54901-8640, USA. - M. R. Forman and W. S. Harploe, Dept of Ecology, Evolution, \& Behavior, Univ. of Minnesota-Twin Cities, St. Paul, MN 55108, USA. - T. Daufresne, Dept of Ecology and Evolutionary Biology, Princeton Univ., Princeton, NJ 08544, USA. - T. Yoshida, Dept of Ecology \& Evolutionary Biology, Cornell Univ., Ithaca, NY 14853, USA.

It has long been recognized that organisms are composed of multiple elements, and that they must obey the laws of mass balance and thermodynamics when transferring elements and energy through trophic levels (Lotka 1925, Lindeman 1942). While the elemental composition (stoichiometry) of plants can be variable, consumers often have a more fixed stoichiometry and can require multiple elements in different ratios than those provided by plants (Sterner and Elser 2002). Hence, net trophic transfer of energy and biomass (both often represented by carbon, C) can be limited by the abundance of other key elements (particularly 
phosphorus, $\mathrm{P}$, and nitrogen, $\mathrm{N}$; often referred to as nutrients). However, until recently, most theoretical and empirical studies of population and community dynamics have not explicitly accounted for this fact. Animal populations, in particular, have often been considered limited by resource quantity, but not by the chemical composition of the resource (but see White 1993). Resource-quantity limitation is a single-currency approach, i.e. trophic transfer is modeled by a single currency such as number of prey individuals, biomass, or $\mathrm{C}$, without considering that this transfer can be linked to the transfer of other elements (such as $\mathrm{P}$ and $\mathrm{N}$ ). The mass balance of multiple elements in chemical reactions can constrain biological processes, and can have major ecological consequences. For example, the highly variable N:C ratios in plants are an important aspect of food quality and can limit growth and reproduction of herbivores and detritivores (White 1993), which might consequently affect demography and dynamics of populations, species interactions and community structure. Ecological stoichiometry, i.e. the study of the balance of multiple chemical substances in ecological interactions and processes (sensu Sterner and Elser 2002), is a new conceptual framework that can improve our understanding of the organization of populations and communities.

A fundamental principle in ecological stoichiometry is that the requirements of multiple elements vary within and among species, and can cause mismatches between demand and supply at ecological interfaces (plant vs inorganic resources, herbivore vs plant, detritivore vs detritus). Stoichiometric mismatches (imbalances in elemental composition) at these interfaces can constrain processes across many levels of ecological organization: individual growth (Elser et al. 1996, Stelzer and Lamberti 2002); population growth (Urabe and Sterner 1996), community dynamics such as trophic transfer and species coexistence (Urabe et al. 2002a); and ecosystem processes such as decomposition and the fate of organic matter (Enriquez et al. 1993, Cebrian 1999). To date, many studies addressing the causes and consequences of elemental imbalances have focused on eco-physiology and life history traits at the level of the individual organism (Frost et al. 2005), but fewer studies have examined their consequences at population and community levels (reviewed by Sterner and Elser 2002, Andersen et al. 2004).

Although single-currency population models (such as Lotka-Volterra-based predator-prey models) can explain many aspects of observed population dynamics, other empirical phenomena cannot be predicted by these models. For example, zooplankton (Daphnia) populations can display positive density dependence (i.e. positive effects of population density on demographic rates) when subject to food with low nutrient content (P:C; Sommer 1992). Intra-specific interactions in this case are shifted from competition towards facilitation: as Daphnia density increases, they can more quickly graze down the algal population (reduce the amount of algal C). With some level of P-recycling by the Daphnia, this results in increased $\mathrm{P}$ availability per algal cell and thus increased algal P:C, which means increased food quality for Daphnia. Laboratory studies have demonstrated that this facilitating mechanism can increase reproductive rates of Daphnia (Sommer 1992) and promote the coexistence of two competing Daphnia species (Urabe et al. 2002a). This facilitation mechanism can be explained by population models that explicitly track the chemical composition (P:C) of the algae (Andersen 1997). A variety of recent studies have shown that incorporation of stoichiometry into population and food-web models can fundamentally change their predictions of population dynamics and species interactions, such as population stability, coexistence of competitors, and alternative steady states of communities (Daufresne and Loreau 2001, Muller et al. 2001, Grover 2003, Hall 2004, Loladze et al. 2004).

Various biochemical and mechanical aspects of food quality have been considered as a limiting factor in population studies (Klemola et al. 2000, Hambäck et al. 2002, McVean et al. 2002), but the elemental aspect of food quality has received less attention (Sterner and Elser 2002). We argue that explicit consideration of stoichiometric constraints in models and empirical studies can enhance our ability to explain how populations and communities operate. Even though our knowledge of stoichiometric effects on population and community levels has been improved by several recent studies (Andersen et al. 2004) there are still large gaps in our knowledge. We identify and explore these gaps in the following general areas: 1) demographic effects: although we know that growth and fecundity can be influenced by stoichiometric constraints, we know far less about how stoichiometry affects other demographic rates such as survival and migration. 2) Population dynamics: we know that incorporation of stoichiometric information in population models can fundamentally change the predicted temporal patterns of population abundances, particularly for two-species consumer-resource systems. How have recent elaborations and extensions of consumer-resource models improved our insight? How might consideration of stoichiometry be incorporated into further modeling efforts? 3) Community dynamics: there is a rich history of stoichiometrically explicit models of resource competition in plant community ecology (Tilman 1982, 1985). Can consideration of stoichiometric constraints increase our understanding of species interactions at higher trophic levels, and of community composition? 
Our objectives with this paper are to:

- review recent progress in knowledge about how stoichiometric constraints affect the structure and dynamics of populations and communities, with emphasis on studies published after Sterner and Elser (2002).

- identify gaps in understanding of how stoichiometry may influence demographic rates, population dynamics and community composition, and propose new questions and hypotheses that could be empirically tested.

- suggest promising directions for new research by recommending potential study systems to improve our understanding of populations and communities.

\section{Stoichiometry and demography}

To understand how stoichiometry can constrain population growth, it is necessary to examine the effects of stoichiometry on different demographic rates (survival, growth, development, reproduction and migration) at different life-history stages. An organism's requirements of different elements may vary throughout its life cycle, and thus certain life stages may be more sensitive than others to variation in the stoichiometry of its resource. Several examples of such effects have recently appeared: Daphnia juveniles have higher body P:C than adults (DeMott 2003); reproductive tissue has higher P:C or $\mathrm{N}: \mathrm{C}$ than somatic tissue in crustaceans (Færøvig and Hessen 2003, Kuijper et al. 2004); low-P food prevented transition between certain copepodid stages in a calanoid copepod (Villar-Argaiz and Sterner 2002), and P-limitation of Daphnia reduces egg size and egg survival (Urabe and Sterner 2001). These data suggest that stoichiometric constraints on a single life-history trait may produce a demographic bottleneck, i.e. this single trait may strongly limit population growth (Urabe and Sterner 2001, Villar-Argaiz and Sterner 2002).

Effects of stoichiometric constraints on individual demographic traits can be linked to population growth rate by life-table response studies (Caswell 2001). However, such links can be more complex than life tables imply, for several reasons. First, the trait that is most constrained by stoichiometry is not necessarily the trait to which population growth rate is most sensitive (sensu Caswell 2001). By analogy, toxicants and other chemical stressors often have the strongest impact on juvenile survival, but this does not necessarily have a strong impact on population growth ("the weakest link incongruity"; Kammenga et al. 1996). Second, the link from individual traits to population growth may be complicated by so-called density-dependent compensations: as reduction in one demographic rate reduces population growth, individuals may benefit from reduced population density, and increases in other density-dependent rates may then to some degree compensate for the initial decrease. For example, if low P:C limits egg production of Daphnia, the density of juveniles competing for algal food will be low, and consequently juvenile survival and growth might increase because of higher food availability per individual. Third, such density-dependent responses in demographic rates can be further complicated by feedback links from consumer population density to food quality (nutrient:C): low food quality may change the density dependence of reproduction from negative to positive, as described earlier (Sommer 1992).

Studies of demographic rates in a stoichiometric context have so far focused on somatic growth, development, and reproduction (Table 1). There is little information available on the effects on survival (but see Kerslake et al. 1998, Nelson et al. 2001). The relationship between stoichiometry and dispersal rates have been considered to an even lesser degree, although spatial processes are important in population ecology (Bjørnstad et al. 1999) and in community ecology (Loreau and Holt 2004). However, it is likely that nutrient deficiencies can affect dispersal and migration processes in various ways (for examples see White 1993). A new challenge is to explore how spatial variation in resource stoichiometry can affect population structure and dynamics via dispersal and migration. One example concerns the diel vertical migration of Daphnia in lakes. At night, when the risk of fish predation is lower than during the day, Daphnia usually migrate up to surface waters where abundant algal food is present and water temperatures are higher. A recent experiment showed that when these algae are nutrient-rich (high P:C), Daphnia would risk predation by migrating up to feed during the day as well as at night (M. R. Forman and R. W. Sterner, unpubl.). This example indicates that spatial heterogeneity of food stoichiometry can affect spatial distribution of consumer populations. A next step could be to investigate how changes in algal stoichiometry indirectly affect growth of predators via the migratory behavior of herbivores.

\section{Stoichiometry and population dynamics of consumer-resource systems}

Stoichiometrically explicit population models of consumer-resource interactions have demonstrated that food elemental composition may have profound effects on population dynamics (Sterner and Elser 2002, Andersen et al. 2004). For example, simple two-species consumer-resource models inherently generate cyclic dynamics, but stoichiometric constraints at the consumer-resource interface may stabilize these dynamics. If a prey population grows (sequesters $\mathrm{C}$ ) at a higher rate than it sequesters a nutrient, the nutrient: $\mathrm{C}$ ratio of the prey will decrease, and may thus limit the growth rate of its predator population. This stoichiometric constraint 
Table 1. Recent studies (not cited by Sterner and Elser 2002) on population and community processes affected by stoichiometric mechanisms. The term "treatment" covers experimental manipulations, observed variations in nature, or changes in model parameters. Although the notation of ratios is standardized as nutrient:C (rather than C:nutrient) in the main text, in order to correlate positively with resource quality, we have kept the authors' original notation of ratios in the table.

Stoichiometric "treatment" $\quad$ Effect on population/community $\quad \begin{gathered}\text { Type of } \\ \text { Type of }\end{gathered}$

(A) Demographic rates or population growth rate

Light:nutrient ratio of environment changes in $\mathrm{C}$ and $\mathrm{P}$ limitation of

$\mathrm{C}: \mathrm{P}$ content of algal food bacteria

$C: P$ ratio of resource

Light:total P in water as an indirect

metric of algal C:P

low somatic growth of herbivores with high C:P, digestion-resistant algae high C:P ratio favors omnivory

high light:total $\mathrm{P}$ decreases herbivore fecundity

P-deficient vs P-sufficient algal food development failure of herbivore with P-deficient food, ontogenetically different responses to P-deficient food low body growth rate of herbivores with high C:P food

$\mathrm{C}: \mathrm{P}$ of algal food

$\mathrm{C}: \mathrm{P}$ of tissues in 2 crustacean species

Various C:P ratios of plant food

$\mathrm{N}: \mathrm{P}$ of algal species

Dietary $\mathrm{C}$ and $\mathrm{N}$ for copepods

Varying P:C of plant food

Exchange of nutrients between organisms and environment

$\mathrm{N}: \mathrm{C}$ and $\mathrm{P}: \mathrm{C}$ ratios of autotroph biomass

P-limitation may reduce egg

production

altered $\mathrm{P}$ supply of insect somatic

tissue

optimal algal $\mathrm{N}: \mathrm{P}$ ratio varies

depending on the resource environment

in N-limited situation, copepods

unable to efficiently use $\mathrm{N}$ to

produce eggs

low P levels may constrain growth and reproduction of tobacco

hornworm

various types of ingestive regulation,

post-ingestive processing, and animal performance

population growth rate increases with

$\mathrm{N}: \mathrm{C}$ and $\mathrm{P}: \mathrm{C}$ ratios in biomass

(B) Resource-consumer interactions

$\mathrm{C}: \mathrm{N}$ ratio of available prey

$\mathrm{N}$ limitation may favor omnivory

$\mathrm{C}: \mathrm{N}: \mathrm{P}$ ratios of a prey and a predator

$\mathrm{C}: \mathrm{N}: \mathrm{P}$ of resource and growth rates

Spatial heterogeneity in soil P:C

(C) Competition between species

$\mathrm{C}$ :nutrient ratios of resource and organisms

$\mathrm{N}: \mathrm{P}$ ratio of resource and herbivore species

Resource N:P ratio

Light and nutrient supply

Gradients of light, $\mathrm{P}$, and predation risk

Nutrient and energy ratios

C:nutrient ratio of resource

(D) Food webs

Light:nutrient ratio of environment $\mathrm{N}$ requirement of species stability of a predator-prey system and its response to enrichment more complicated responses of bacterial C:N:P at community than individual levels

consumer can cause resource

extinction in P-poor patch

preventing coexistence of producers and decomposers

competitive outcome of two algal species

competitive outcome and population dynamics of two bacterial competitors competitive outcome of two herbivores

effects of $\mathrm{P}$ on composition of herbivore species

influences on coexistence of consumers allowing coexistence of competitors

food-web structure

diversity-productivity relationship

\begin{tabular}{|c|c|c|}
\hline field & freshwater & $\begin{array}{l}\text { Chrzanowski and } \\
\text { Grover } 2001\end{array}$ \\
\hline field & freshwater & $\begin{array}{l}\text { DeMott and Tessier } \\
2002\end{array}$ \\
\hline field & freshwater & Gaedke et al. 2002 \\
\hline field & freshwater & Scheuerell et al. 2002 \\
\hline lab & freshwater & $\begin{array}{l}\text { Villar-Argaiz and } \\
\text { Sterner } 2002\end{array}$ \\
\hline lab & freshwater & DeMott 2003 \\
\hline lab & freshwater & $\begin{array}{l}\text { Færøvig and Hessen } \\
2003\end{array}$ \\
\hline field & terrestrial & Schade et al. 2003 \\
\hline model & marine & Klausmeier et al. 2004 \\
\hline model & marine & Kuijper et al. 2004 \\
\hline lab & terrestrial & Perkins et al. 2004 \\
\hline model & terrestrial & $\begin{array}{l}\text { Raubenheimer and } \\
\text { Simpson } 2004\end{array}$ \\
\hline model & $\begin{array}{l}\text { freshwater/ } \\
\text { terrestrial }\end{array}$ & Ågren 2004 \\
\hline field & terrestrial & $\begin{array}{l}\text { Denno and Fagan } \\
2003\end{array}$ \\
\hline model & freshwater & Grover 2003 \\
\hline lab & freshwater & $\begin{array}{l}\text { Makino and Cotner } \\
2004\end{array}$ \\
\hline model & generic & Miller et al. 2004 \\
\hline
\end{tabular}

\begin{tabular}{|c|c|c|}
\hline $\begin{array}{l}\text { model } \\
\text { model }\end{array}$ & $\begin{array}{l}\text { generic } \\
\text { freshwater }\end{array}$ & $\begin{array}{l}\text { Daufresne and Loreau } \\
2001 \\
\text { Grover } 2002\end{array}$ \\
\hline model & freshwater & Grover 2004 \\
\hline $\begin{array}{l}\text { model } \\
\text { field }\end{array}$ & $\begin{array}{l}\text { generic } \\
\text { freshwater }\end{array}$ & $\begin{array}{l}\text { Hall } 2004 \\
\text { Hall et al. } 2004\end{array}$ \\
\hline $\begin{array}{l}\text { model } \\
\text { model }\end{array}$ & $\begin{array}{l}\text { generic } \\
\text { generic }\end{array}$ & $\begin{array}{l}\text { Kooijman et al. } 2004 \\
\text { Loladze et al. } 2004\end{array}$ \\
\hline $\begin{array}{l}\text { field } \\
\text { field }\end{array}$ & $\begin{array}{l}\text { freshwater } \\
\text { terrestrial }\end{array}$ & $\begin{array}{l}\text { Elser et al. } 2003 \\
\text { Hille Ris Lambers } \\
\text { et al. } 2004\end{array}$ \\
\hline
\end{tabular}

can prevent the consumer population from overshooting the carrying capacity and having a subsequent population crash (Hessen and Bjerkeng 1997). On the other hand, recent theoretical studies have demonstrated that stoichiometric constraints can generate a rich range of dynamics, including sustained population cycles, 
multiple attractors, chaos, and consumer extinction. Stoichiometrically explicit population models and empirical tests of these predictions have been reviewed recently by Andersen et al. (2004) as well as by Sterner and Elser (2002). We will therefore only briefly describe the fundamental properties of such models here, together with new insights from recent studies. Table 1 includes other theoretical studies that analyze effects of stoichiometric constraints at the population level. We will also suggest other aspects of population biology that might be considered in stoichiometrically explicit population models to improve ecological realism and insight.

Many of the stoichiometrically explicit population models to date (Table 1) represent a plant-herbivore system cultured in a chemostat with a constant dilution rate (inflow of a nutrient medium and outflow of the whole system), such as the algae-Daphnia model by Andersen (1997). Certain properties are common for most of these models. Plant growth is limited by availability of an inorganic nutrient (e.g. P) and by its own carrying capacity. Plant P:C can vary, whereas the herbivore is homeostatic (has constant P:C). The limiting factor for herbivore growth can switch between plant quantity (C) and plant quality (P:C). One critical question is: how does $\mathrm{P}$ enrichment affect this system? Algal C and P:C are both positively related to $\mathrm{P}$ input, but since $\mathrm{P}: \mathrm{C}$ also decreases with increasing $\mathrm{C}$, the net effect on algal P:C and thus on herbivore growth is not obvious. In general, increased P input increases the algal carrying capacity and causes the herbivore population to cycle with increasing amplitude, by the same mechanism as the classical "paradox of enrichment" model (Rosenzweig 1971). However, stoichiometric constraints on the consumer can add more complexity to this paradox: high $\mathrm{P}$ input can cause algal $\mathrm{C}$ to increase more rapidly than algal $\mathrm{P}: \mathrm{C}$ and the limiting factor for the herbivore population is shifted from food quantity to quality ( $\mathrm{C}$ to $\mathrm{P}: \mathrm{C})$. This trend may be self-reinforcing: low food quality limits the herbivore growth and thus the grazing pressure on the algal population declines; hence, algal C can continue to increase while its P:C decreases. As a result, the consumer population may eventually be driven to extinction due to low food quality, while the algal population persists.

Most of the stoichiometrically explicit consumerresource models give similar predictions as described above: increasing nutrient enrichment destabilizes the herbivore dynamics and can eventually cause extinction or prevent invasion (Hessen and Bjerkeng 1997, Loladze et al. 2000, 2004, Muller et al. 2001, Grover 2002, 2003, 2004, Bandyopadhyay et al. 2004, Hall et al. 2004). These qualitative predictions also seem robust to variation in model assumptions, such as whether the consumer is completely homeostatic or not (Grover 2003), and whether the interaction is modeled in discrete time rather than in continuous time (Fan et al. in press).
However, most of these models have a critical assumption in common: the threshold function that switches abruptly between food quantity and food quality limitation. Such threshold functions corresponding to Liebig's minimum principle are easily comprehensible, but imply elbow-shaped isoclines, which can have strong bearings on the model predictions (Andersen et al. 2004, Hall 2004). This problem can be amended by using "smoother" functions, i.e. that allow for simultaneous $\mathrm{C}$ and $\mathrm{P}$ limitation during a transition from low $\mathrm{C}$ to high C. An example of such an attempt are the "synthesizing units", which are the functional relationships that describe the ratios in which multiple elements are assimilated or used for growth, introduced by dynamic energy budget (DEB) models (Kooijman et al. 2004). Although this approach adds complexity and introduces abstract concepts, it can give a better mechanistic basis for demographic responses to stoichiometric constraints, and strengthen the inferences that can be made from the model analyses (Muller et al. 2001, Hanegraaf and Kooi 2002, Kuijper et al. 2004). Nevertheless, models based on DEB theory (Muller et al. 2001) have given qualitatively similar predictions as stoichiometrically explicit models using threshold functions (Andersen 1997).

There are many aspects of population ecology that remain to be comprehensively considered in a stoichiometric context: for example, physiological or demographic structure (De Roos and Persson 2001), spatial structure (Bjørnstad et al. 1999) and demographic and/ or environmental stochasticity (de Valpine and Hastings 2002). Most stoichiometrically explicit models have treated populations as a pool of elements and thereby ignored any population structure (age, stage, size). However, variability among individuals can influence the outcome of resource limitation. For example, populations where competitive strength varies among individuals tend to have more stable dynamics than populations where limiting resources are partitioned more equally (contest vs scramble competition, Nicholson 1954). Use of individual-based population models (Mooij and Boersma 1996, Lomnicki 1999) might be a way to track individual changes in stoichiometry, effects on individual competitive abilities for different elements and consequences for population dynamics. As a first approach, a physiologically or demographically structured model (Tuljapurkar and Caswell 1997) could be used to track such stoichiometric and competitive properties for groups within a population. For example, there could be asymmetric competition for $\mathrm{P}$ between juvenile and adult individuals in copepod populations: juveniles require more $\mathrm{P}$ per unit body mass $(\mathrm{C})$ than adults, although they also require less C per unit body mass (Villar-Argaiz and Sterner 2002). The outcome of such asymmetric competition for $\mathrm{P}$ (vs uniform competition) for total population biomass 
(C) is not obvious. The total biomass might be lower because $\mathrm{P}$ limitation of juveniles reduces their efficiency of $\mathrm{C}$ assimilation, or it might be higher because this asymmetric $\mathrm{P}$ competition allows for better $\mathrm{C}$ utilization by adults. Scenarios like this could be explored using a model that is both stoichiometrically explicit and distinguishes between the juvenile and adult groups.

Spatially explicit population models have often considered heterogeneous environments as habitable patches embedded in uninhabitable surroundings (Hanski 1998). The stoichiometric framework provides an opportunity to model habitat quality in a more mechanistic way. The only pertinent example to our knowledge is the spatially and stoichiometrically explicit model by Miller et al. (2004), which demonstrated that spatial heterogeneity in soil $\mathrm{P}$ levels in combination with consumer dispersal can have important implications for the persistence of local plant populations. In this analysis, the authors assume that there is one P-poor and one P-rich patch, that low soil P limits both plant growth (C) and plant P:C, and that both plant $\mathrm{C}$ and plant P:C limit consumer growth. In a conventional setting, consumers dispersing from a resource-rich patch can depress plant growth in a resource-poor patch and cause local extinction by "apparent competition" (Holt 1984). However, Miller et al. (2004) show that stoichiometric constraints can modify this outcome: if the overall consumer growth is limited by $\mathrm{P}: \mathrm{C}$ in the two patches, the consumer may not be able to over-graze the P-poor patch, and this may prevent the local extinction of the P-poor plant population. In this way, stoichiometric mechanisms may influence the persistence of fragmented communities (Miller et al. 2004). A further extension of this modeling path could be to consider effects of consumer dispersal on local habitat's nutrient: $\mathrm{C}$ ratios by consumer-driven nutrient recycling, and thus explore spatial patterns in feedback mechanisms between dispersing organisms and habitat quality (Reissig et al. 2003). For example, if consumers spend more time in patches where the resource quality is higher, will this increase the local nutrient recycling by consumers, and cause a positive feedback that enhances the spatial heterogeneity in resource stoichiometry?

\section{Stoichiometry, species interactions and community dynamics}

The consequences of stoichiometry for consumerresource interactions have been thoroughly addressed by a body of theoretical and experimental studies, mainly focusing on autotroph-herbivore dynamics (Andersen et al. 2004) as described in the previous section. However, stoichiometric constraints may affect interactions between species regardless of the trophic level or the functional group involved (Grover 1997). Applications of ecological stoichiometry at the community level demonstrate the complexity of nutrient- and energymediated interactions among species. Stoichiometric constraints can alter species interactions by influencing the rate of transfer of matter and energy between trophic levels, and by affecting the balance between positive and negative inter-specific effects. Here we focus on three types of species interactions that have received less stoichiometric attention: competition between plants in combination with nutrient recycling, competition between consumers, and competition between different guilds (plants and decomposers; herbivores and omnivores).

A stoichiometrically explicit approach for plant interactions, the resource-ratio theory (Tilman 1982), has long been used to predict the outcomes of plant competition for nutrients and light. This theory has recently been extended to account for nutrient recycling. For example, T. Daufresne and L. Hedin (unpubl.) have shown that plants can modify the outcomes of competition through their ability to influence the stoichiometry of decomposer-driven recycling: coexistence is facilitated if plants promote more recycling of the nutrient that limits their competitors. Consumer-mediated recycling also has important consequences for the outcome of plant competition. For example, although two resource species may coexist by stoichiometric mechanisms when competing for $\mathrm{N}$ and $\mathrm{P}$ depending on the external supply ratio of $\mathrm{N}$ and $\mathrm{P}$ (Tilman 1982), the inferior P-competitor (e.g. cyanobacteria) can be driven to competitive exclusion in the presence of a consumer (Daphnia) that recycles at a high N:P ratio (Grover 2002) and thus promotes $\mathrm{P}$ limitation and extinction of the resource species with less efficient $\mathrm{P}$ uptake.

Recent stoichiometric studies of species interactions can be viewed as resource-ratio theory applied to higher trophic levels. With a stoichiometrically explicit model, Hall (2004) addressed the outcome of competition by herbivore species sharing a plant resource. He showed that nutrient: $\mathrm{C}$ ratios in plants affect the outcomes of herbivore competition in a similar way to what occurs in classical resource-ratio theory for autotrophs: herbivore species can exclude each other, or stably coexist, depending on their requirements for $\mathrm{C}$ and nutrients, and on the nutrient: $\mathrm{C}$ ratio in plant biomass. Hence, if two competitors consume a single resource species, classical one-currency model will predict coexistence to be impossible (by virtue of the competitive exclusion principle), whereas a stoichiometrically explicit model demonstrates that coexistence is possible. In a similar approach with two herbivore species and a single plant species, Loladze et al. (2004) showed cases of stable coexistence with both herbivores limited by the same nutrient in the plant biomass. These models indicate that variations in stoichiometric food quality can promote species coexistence in nature, by adding an extra 
dimension along which species' competitive abilities can vary and by shifting species interactions from competition (when food is of good quality but low in abundance) to facilitation (when food is abundant but of poor quality). These theoretical results are supported by the study of Urabe et al. (2002a), which showed that low food quality (P:C) promotes coexistence of two Daphnia species.

Extensions of the resource-ratio theory also concern competition between different guilds, such as competition between plants and decomposers or between herbivores and omnivores. Plants generally have lower $\mathrm{N}: \mathrm{C}$ and $\mathrm{P}: \mathrm{C}$ ratios than required by decomposers. However, microbial decomposers can take up inorganic $\mathrm{N}$ and $\mathrm{P}$, and thereby compete with plants for these limiting resources. Theoretical studies (Thingstad and Pengerud 1985, Daufresne and Loreau 2001) have shown that the coexistence of plants and decomposers requires that decomposers are better competitors for nutrients and therefore remain limited by the carbon provided by the plants. Ecological stoichiometry has also shed new light on omnivorous strategies in food webs (Denno and Fagan 2003, Diehl 2003) and mixotrophy in planktonic food webs (Ptacnik et al. 2004). Using a model with two consumers and one resource, Diehl (2003) showed that two important prerequisites for omnivory to emerge are that 1) the consumers must be able to coexist and 2) omnivory must be beneficial. Hence, omnivory is more likely to occur if the consumers are nutrient-limited rather than energy-limited, because 1) nutrient limitation promotes coexistence of competitors (as mentioned earlier) and 2) nutrient limitation may induce a consumer to switch from herbivory to predation on another consumer, since consumer biomass is generally of higher nutritional quality than plant biomass. Indeed, disparities in N:C between consumers and prey have suggested that terrestrial arthropod consumers that frequently show omnivory may be nitrogen-limited (Denno and Fagan 2003, Fagan and Denno 2004). Arthropod omnivores can increase their growth by feeding on nitrogen-rich prey, although this is not always the case in nature (Matsumura et al. 2004).

Stoichiometrically explicit population models have so far been limited to a few interacting species, possibly for technical reasons. The application of network analysis (Milo et al. 2004) to food webs can give insights into how ecological communities are structured and respond to changes (Borer et al. 2002). Inspired by the fact that metabolic network models have explicit stoichiometric constraints (Schilling et al. 2000), we suggest that network models with stoichiometric constrains might be worth exploring also for food webs. The links in a network can be weighted according to different criteria, such as interaction strength or efficiency of carbon transfer. Moreover, improved understanding from ecological stoichiometry might allow interaction strength to be predicted rather than incorporated ad hoc or post hoc from empirical data. The sensitivity of the network properties (such as stability or connectivity) to removal of a certain node or a link can then be influenced by this weight. We propose that food-web links (representing C transfer) at different trophic levels could be weighted differently according to strength of stoichiometric constraints: e.g. the link from plants to herbivores or detritivore could be weighted low because of $\mathrm{N}$ limitation on $\mathrm{C}$ transfer, whereas links from these consumers to carnivores could be weighted high because this $\mathrm{C}$ transfer is more efficient. Stoichiometrically weighted food-web models might then provide new insights into how constraints by different elements may affect trophic transfer efficiency, community connectivity, and network stability.

\section{New directions for stoichiometry at population and community levels}

\section{Application of stoichiometry to more study systems}

Our ability to generalize ecological stoichiometry across natural systems is constrained by the research attention and emphasis that different taxa or community types receive. Of the empirical studies considering how stoichiometry influences population and community dynamics, most have been in aquatic systems (reviewed by Sterner and Elser 2002). While the importance of C:N ratios has been a mainstay of the terrestrial herbivory and decomposition literature (Mattson 1980, Enriquez et al. 1993, Hobbie 2000), the influence of stoichiometry on population and community dynamics of terrestrial animals, in particular, has rarely been considered (Throop and Lerdau 2004). Here we will consider three examples of groups or systems where consideration of stoichiometry would likely increase understanding of population and community dynamics: terrestrial insects, detritivore food webs and soil communities.

Since insects vary considerably in elemental composition among taxa (Fagan et al. 2002, Fagan and Denno 2004, Evans-White et al. 2005), and require diverse food resources both among species and through life cycles, one could expect substantial variation in the degree of stoichiometric constraints on their population growth (Hodar et al. 2002, Schade et al. 2003). Possible relationships between stoichiometry and population outbreaks could be of particular interest, since insect populations are responsible for considerable damage to forests throughout the world (Peltonen et al. 2002). Although studies of insect outbreaks consider some aspects of food quality, such as herbivore-induced defenses, they rarely consider the influence of food stoichiometry (Ylioja et al. 1999, Dwyer et al. 2004, but see Kerslake et al. 1998). However, small scale experiments show that foliar 
elemental composition, which can vary considerably spatially (Osier et al. 2000a), temporally (Osier et al. 2000b) and among species (Son and Gower 1992), can influence the somatic growth and development of outbreaking insects (Hemming and Lindroth 1995, Carisey and Bauce 2002). In light of this evidence, it would be instructive to consider the role of stoichiometric constraints in future studies of insect outbreaks.

Detritus-based food webs have received far less attention than herbivory-driven webs, yet they contribute substantially to trophic flows and element cycling in ecosystems (Hessen et al. 2004). Less than $20 \%$ of global net primary production is consumed by herbivores; the remaining $80 \%$ enters the detrital food web and indeed, this fraction itself appears to be under stoichiometric control (Cebrian 1999). How does the detritus-detritivore interaction differ from the grazing food web from a stoichiometric perspective? Since detritus generally has lower N:C and P:C than live plant material, stoichiometric imbalances could be even more important for detritus-detritivore interactions (Cross et al. 2003, Evans-White et al. 2005). Moreover, because the elemental composition of detritus changes over the course of decomposition (Hobbie 2000), there are opportunities for feeding specialization by decomposers along a stoichiometric axis, which may contribute to diversity of detritivore species (Moore et al. 2004).

Stoichiometric constraints in belowground food webs may be as great as in the aboveground webs, but are less studied. A terrestrial soil system may consist of several interacting guilds (producers, decomposers, mycorrhizae, belowground herbivores, pathogens, predators and $\mathrm{N}$-fixers), with potentially very different stoichiometric requirements and impacts. Many of these interactions can involve mismatches in stoichiometry between interacting organisms. For example, mutualistic interactions can be modeled as economic transactions between organisms with differential access to elements: plants have abundant access to $\mathrm{C}$, which can be traded with mycorrhizae for P or with $\mathrm{N}$-fixers for $\mathrm{N}$ (Bloom et al. 1985, Sterner and Elser 2002). Because soil communities can be highly complex (Pokarzhevskii et al. 2003), and largely dependent on the inherent physical and chemical properties of soils (parent material, cation exchange, nutrient diffusion), soil communities seem to us to be a fertile area for stoichiometric-based research.

\section{Limitations of ecological stoichiometry and alternative explanations}

Although consideration of stoichiometric constraints will often improve our understanding of population and community dynamics, there are obviously many situation where stoichiometry will not offer increased explanatory power. For example, DeMott and Tessier
(2002) considered several alternative explanations for among-lake differences in somatic growth of Daphnia. Experimentally increasing the $\mathrm{P}$ content of $\mathrm{P}$-poor seston did not increase Daphnia somatic growth. Instead, the difference in Daphnia growth among lakes was attributed to energy limitation due to differences in food digestibility. Hall et al. (2004) found that body P content of zooplankton species could not explain all the observed effect of nutrient and light manipulations on composition of zooplankton communities, which challenges predictions of ecological stoichiometry. Suggested explanations were that 1) some species can use P-rich bacteria as alternative food to P-poor algae, and 2) other traits than elemental body composition of herbivores influence their competitive abilities for nutrients. Another example considers population dynamics of algae and rotifer herbivores. Although $\mathrm{N}$ limitation was known to produce low-quality algal food for rotifer herbivores, theoretical analyses incorporating stoichiometric effects of algal food on herbivore growth did not provide a better explanation for the observed population dynamics. An alternative biological mechanism (rapid evolution of algae) better explained the cyclic consumerresource dynamics than algal stoichiometry (Shertzer et al. 2002, Yoshida et al. 2003). Other food quality factors that may mask or override potential effects of stoichiometry include the "quality of carbon", i.e. whether carbon is in a chemically available form, and the fatty acid content (Muller-Navarra et al. 2004). The above examples highlight the need to consider stoichiometric constraints as one of many alternative drivers of population and community dynamics.

\section{Concluding remarks}

In this paper we have (1) reviewed recent progress in the application of ecological stoichiometry to the population and community levels, (2) highlighted gaps in our understanding and (3) suggested new directions for further development of this field. While relationships between nutrient:carbon ratios and certain demographic rates such as somatic growth and reproduction are documented, little is known about how stoichiometric constraints affect other key aspects of demography such as mortality and dispersal behavior. An increasing number of stoichiometrically explicit models have provided insight into the effects of stoichiometry on the mechanisms governing population dynamics, species interactions, and the maintenance of species diversity. However, few studies to date have considered aspects such as individual variation, demographic structure, or spatial structure in populations. Empirical examples show that stoichiometric constraints can influence various types of species interactions, including competition between different types of consumers. However, 
there are many predictions of stoichiometric models that still need to be tested. For example, several models predict that lower nutrient:carbon ratios in food resources promote coexistence of competing consumers, but the patterns may be complicated by factors such as intra-guild predation and competition between apparently different trophic levels. Additional theoretical elaborations on, and empirical tests of, species interactions in different types of food-web configurations would improve our ability to establish the generality of these stoichiometric predictions. Finally, our review shows that while freshwater plankton communities are relatively well-studied from a stoichiometric perspective, more studies of certain major taxa (insects) and of types of communities (such as detritus-based food webs and soil communities) within a stoichiometric framework are needed, both because of their important roles in ecosystems and because evidence indicates that stoichiometric constraints are likely to be important.

Acknowledgements - This paper is a product of the workshop "Woodstoich 2004-The present and future of Ecological Stoichiometry", funded by the Centre for Advanced Studies at the Norwegian Academy of Science and Letters. Present at the workshop were SJM (moderator), RSS, MRF and TY. We thank Jon Benstead for early contributions and Jim Elser, Dag Hessen, Tim Lenton, Søren Larsen and other participants of Woodstoich 2004. SJM thanks the National Center for Ecological Analysis and Synthesis, University of California for support. The Graduate Program of Water Resources Science at the University of Minnesota and the Faculty Development Program at the University of Wisconsin Oshkosh provided additional travel grants to MRF and RSS, respectively.

\section{References}

Andersen, T. 1997. Pelagic nutrient cycles: herbivores as sources and sinks. - Springer.

Andersen, T., Elser, J. J. and Hessen, D. O. 2004. Stoichiometry and population dynamics. - Ecol. Lett. 7: 884-900.

Bandyopadhyay, M., Bhattacharyya, R. and Mukhopadhyay, B. 2004. Dynamics of an autotroph-herbivore ecosystem with nutrient recycling. - Ecol. Modell. 176: 201-209.

Bjørnstad, O. N., Ims, R. A. and Lambin, X. 1999. Spatial population dynamics: analyzing patterns and processes of population synchrony. - Trends Ecol. Evol. 14: 427-432.

Bloom, A. J., Chapin, F. S., III and Mooney, H. A. 1985. Resource limitation in plants-an economic analogy. - Annu. Rev. Ecol. Syst. 16: 363-392.

Borer, E. T., Anderson, K., Blanchette, C. A. et al. 2002. Topological approaches to food web analysis: a few modifications may improve our insights. - Oikos 99: 397-401.

Carisey, N. and Bauce, E. 2002. Does nutrition-related stress carry over to spruce budworm, Choristoneura fumiferana (Lepidoptera: Tortricidae) progeny? - Bull. Entomol. Res. 92: $101-108$.

Caswell, H. 2001. Matrix population models: construction, analysis, and interpretation. - Sinauer Associates.

Cebrian, J. 1999. Patterns in the fate of production in plant communities. - Am. Nat. 154: 449-468.

Chrzanowski, T. H. and Grover, J. P. 2001. The light: nutrient ratio in lakes: a test of hypothesized trends in bacterial nutrient limitation. - Ecol. Lett. 4: 453-457.
Cross, W. F., Benstead, J. P., Rosemond, A. D. et al. 2003. Consumer-resource stoichiometry in detritus-based streams. - Ecol. Lett. 6: 721-732.

Daufresne, T. and Loreau, M. 2001. Ecological stoichiometry, primary producer-decomposer interactions, and ecosystem persistence. - Ecology 82: 3069-3082.

De Roos, A. M. and Persson, L. 2001. Physiologically structured models-from versatile technique to ecological theory. - Oikos 94: 51-71.

de Valpine, P. and Hastings, A. 2002. Fitting population models incorporating process noise and observation error. - Ecol. Monogr. 72: 57-76.

DeMott, W. R. 2003. Implications of element deficits for zooplankton growth. - Hydrobiologia 491: 177-184.

DeMott, W. R. and Tessier, A. J. 2002. Stoichiometric constraints vs algal defenses: testing mechanisms of zooplankton food limitation. - Ecology 83: 3426-3433.

Denno, R. F. and Fagan, W. F. 2003. Might nitrogen limitation promote omnivory among carnivorous arthropods? - Ecology 84: $2522-2531$.

Diehl, S. 2003. The evolution and maintenance of omnivory: dynamic constraints and the role of food quality. - Ecology 84: $2557-2567$.

Dwyer, G., Dushoff, J. and Yee, S. H. 2004. The combined effects of pathogens and predators on insect outbreaks. - Nature 430: 341-345.

Elser, J. J., Dobberfuhl, D. R., MacKay, N. A. et al. 1996. Organism size, life history, and N:P stoichiometry. - Bioscience 46: 674-684.

Elser, J. J., Kyle, M., Makino, W. et al. 2003. Ecological stoichiometry in the microbial food web: a test of the light:nutrient hypothesis. - Aquat. Microbial Ecol. 31: $49-65$.

Enriquez, S., Duarte, C. M. and Sand-Jensen, K. 1993. Patterns in decomposition rates among photosynthetic organisms: the importance of detritus C:N:P content. - Oecologia 94: $457-471$.

Evans-White, M. A., Stelzer, R. S. and Lamberti, G. A. 2005. Taxonomic and regional patterns in benthic macroinvertebrate elemental composition in streams. - Freshwater Biology (in press).

Fagan, W. F. and Denno, R. F. 2004. Stoichiometry of actual vs potential predator-prey interactions: insights into nitrogen limitation for arthropod predators. - Ecol. Lett. 7: 876-883.

Fagan, W. F., Siemann, E., Mitter, C. et al. 2002. Nitrogen in insects: implications for trophic complexity and species diversification. - Am. Nat. 160: 784-802.

Fan, M., Loladze, I., Kuang, Y. et al. in press. Dynamics of a stoichiometric discrete producer-grazer model. - J. Difference Eq. Appl.

Frost, P. C., Evans-White, M. A., Finkel, Z. V. et al. 2005. Are you what you eat? Physiological constraints on organismal stoichiometry in an elementally imbalanced world. - Oikos 109: $18-28$.

Færøvig, P. J. and Hessen, D. O. 2003. Allocation strategies in crustacean stoichiometry: the potential role of phosphorus in the limitation of reproduction. - Freshwater Biol. 48: $1782-1792$.

Gaedke, U., Hochstaedter, S. and Straile, D. 2002. Interplay between energy limitation and nutritional deficiency: empirical data and food web models. - Ecol. Monogr. 72: 251 270 .

Grover, J. P. 1997. Resource Competition. - Chapman and Hall.

Grover, J. P. 2002. Stoichiometry, herbivory and competition for nutrients: Simple models based on planktonic ecosystems. - J. Theor. Biol. 214: 599-618.

Grover, J. P. 2003. The impact of variable stoichiometry on predator-prey interactions: a multinutrient approach. - Am. Nat. 162: 29-43.

Grover, J. P. 2004. Predation, competition, and nutrient recycling: a stoichiometric approach with multiple nutrients. - J. Theor. Biol. 229: 31-43. 
Hall, S. R. 2004. Stoichiometrically explicit competition between grazers: species replacement, coexistence, and priority effects along resource supply gradients. - Am. Nat. 164: $157-172$.

Hall, S. R., Leibold, M. A., Lytle, D. A. et al. 2004 Stoichiometry and planktonic grazer composition over gradients of light, nutrients, and predation risk. - Ecology 85: 2291-2301.

Hambäck, P. A., Grellmann, D. and Hjältén, J. 2002. Winter herbivory by voles during a population peak: the importance of plant quality. - Ecography 25: 74-80.

Hanegraaf, P. P. F. and Kooi, B. W. 2002. The dynamics of a tritrophic food chain with two-component populations from a biochemical perspective. - Ecol. Modell. 152: 47-64

Hanski, I. 1998. Metapopulation dynamics. - Nature 396: 4149.

Hemming, J. D. C. and Lindroth, R. L. 1995. Intraspecific variation in aspen phytochemistry-effects on performance of gypsy moths and forest tent caterpillars. - Oecologia 103: $79-88$.

Hessen, D. O. and Bjerkeng, B. 1997. A model approach to planktonic stoichiometry and consumer-resource stability. - Freshwater Biol. 38: 447-471.

Hessen, D. O., Ågren, G. I., Anderson, T. R. et al. 2004. Carbon, sequestration in ecosystems: the role of stoichiometry. - Ecology 85: 1179-1192.

Hille Ris Lambers, J., Harpole, W. S., Tilman, D. et al. 2004. Species and mechanisms contributing to the positive diversity-productivity relationship. - Ecol. Lett. 7: 661-668.

Hobbie, S. E. 2000. Interactions between litter lignin and soil nitrogen availability during leaf litter decomposition in a Hawaiian montane forest. - Ecosystems 3: 484-494.

Hodar, J. A., Zamora, R. and Castro, J. 2002. Host utilisation by moth and larval survival of pine processionary caterpillar Thaumetopoea pityocampa in relation to food quality in three Pinus species. - Ecol. Entomol. 27: 292-301.

Holt, R. D. 1984. Spatial heterogeneity, indirect interactions, and the coexistence of prey species. - Am. Nat. 124: $377-$ 406.

Hubbell, S. 2001. The unified neutral theory of biodiversity and biogeography. - Princeton Univ. Press.

Kammenga, J. E., Busschers, M., VanStraalen, N. M. et al. 1996. Stress induced fitness reduction is not determined by the most sensitive life-cycle trait. - Funct. Ecol. 10: 106111.

Kerslake, J. E., Woodin, S. J. and Hartley, S. E. 1998. Effects of carbon dioxide and nitrogen enrichment on a plant-insect interaction: the quality of Calluna vulgaris as a host for Operophtera brumata. - New Phytol. 140: 43-53.

Klausmeier, C. A., Litchman, E., Daufresne, T. et al. 2004. Optimal nitrogen-to-phosphorus stoichiometry of phytoplankton. - Nature 429: 171-174.

Klemola, T., Norrdahl, K. and Korpimäki, E. 2000. Do delayed effects of overgrazing explain population cycles in voles? - Oikos 90: 509-516.

Kooijman, S. A. L. M., Andersen, T. and Kooi, B. W. 2004 Dynamic energy budget representations of stoichiometric constraints on population dynamics. - Ecology 85: 12301243

Kuijper, L. D. J., Anderson, T. R. and Kooijman, S. A. L. M. 2004. C and $\mathrm{N}$ gross growth efficiencies of copepod egg production studied using a dynamic energy budget model. - J. Plankton Res. 26: 213-226.

Lindeman, R. 1942. The trophic-dynamic aspect of ecology. - Ecology 23: 399-418

Loladze, I., Kuang, Y. and Elser, J. J. 2000. Stoichiometry in producer-grazer systems: linking energy flow with element cycling. - Bull. Math. Biol. 62: 1137-1162.

Loladze, I., Kuang, Y., Elser, J. J. et al. 2004. Competition and stoichiometry: coexistence of two predators on one prey. - Theor. Popul. Biol. 65: 1-15.
Lomnicki, A. 1999. Individual-based models and the individualbased approach to population ecology. - Ecol. Modell. 115: $191-198$.

Loreau, M. and Holt, R. D. 2004. Spatial flows and the regulation of ecosystems. - Am. Nat. 163: 606-615.

Lotka, A. J. 1925. Elements of physical biology. - Williams and Wilkins.

Makino, W. and Cotner, J. B. 2004. Elemental stoichiometry of a heterotrophic bacterial community in a freshwater lake: implications for growth- and resource-dependent variations. - Aquat. Microbial Ecol. 34: 33-41.

Makino, W., Urabe, J., Elser, J. J. et al. 2002. Evidence of phosphorus-limited individual and population growth of Daphnia in a Canadian shield lake. - Oikos 96: 197-205.

Mattson, W. J. 1980. Herbivory in relation to plant nitrogen content. - Annu. Rev. Ecol. Syst. 11: 119-161.

Matsumura, M., Trafelet-Smith, G. M., Gratton, C. et al. 2004. Does intraguild predation enhance predator performance? A stoichiometric perspective. - Ecology 85: 2601-2615.

McVean, R. I. K., Sait, S. M., Thompson, D. J. et al. 2002. Effects of resource quality on the population dynamics of the Indian meal moth Plodia interpunctella and its granulovirus. - Oecologia 131: 71-78.

Miller, C. R., Kuang, Y., Fagan, W. F. et al. 2004. Modeling and analysis of stoichiometric two-patch consumer-resource systems. - Math. Biosci. 189: 153-184.

Milo, R., Itzkovitz, S., Kashtan, N. et al. 2004. Superfamilies of evolved and designed networks. - Science 303: 15381542

Mooij, W. M. and Boersma, M. 1996. An object-oriented simulation framework for individual-based simulations (OSIRIS): Daphnia population dynamics as an example, Ecol. Modell. 93: 139-153.

Moore, J. C., Berlow, E. L., Coleman, D. C. et al. 2004. Detritus, trophic dynamics and biodiversity. - Ecol. Lett. 7: 584-600.

Muller, E. B., Nisbet, R. M., Kooijman, S. A. L. M. et al. 2001. Stoichiometric food quality and herbivore dynamics. - Ecol. Lett. 4: 519-529.

Muller-Navarra, D. C., Brett, M. T., Park, S. et al. 2004. Unsaturated fatty acid content in seston and trophodynamic coupling in lakes. - Nature 427: 69-72.

Nelson, W. A., McCauley, E. and Wrona, F. J. 2001. Multiple dynamics in a single predator-prey system: experimental effects of food quality. - Proc. R. Soc. Lond. Ser. B 268: $1223-1230$.

Nicholson, A. J. 1954. An outline of the dynamics of animal populations. - Aust. J. Zoo. 2: 9-65.

Osier, T. L., Hwang, S. Y. and Lindroth, R. L. 2000a. Effects of phytochemical variation in quaking aspen Populus tremuloides clones on gypsy moth Lymantria dispar performance in the field and laboratory. - Ecol. Entomol. 25: 197-207.

Osier, T. L., Hwang, S. Y. and Lindroth, R. L. 2000b. Withinand between-year variation in early season phytochemistry of quaking aspen (Populus tremuloides Michx.) clones. - Biochem. Syst. Ecol. 28: 197-208.

Peltonen, M., Liebhold, A. M., Bjørnstad, O. N. et al. 2002. Spatial synchrony in forest insect outbreaks: roles of regional stochasticity and dispersal. - Ecology 83: 31203129.

Perkins, M. C., Woods, H. A., Harrison, J. F. et al. 2004. Dietary phosphorus affects the growth of larval Manduca sexta. - Arch. Insect Biochem. Physiol. 55: 153-168.

Pokarzhevskii, A. D., van Straalen, N. M., Zaboev, D. P. et al. 2003. Microbial links and element flows in nested detrital food-webs. - Pedobiologia 47: 213-224.

Ptacnik, R., Sommer, U., Hansen, T. et al. 2004. Effects of microzooplankton and mixotrophy in an experimental planktonic food web. - Limnol. Oceanogr. 49: $1435-1445$.

Raubenheimer, D. and Simpson, S. J. 2004. Organismal stoichiometry: quantifying non-independence among food components. - Ecology 85: 1203-1216. 
Reissig, M., Queimalinos, C. P. and Balseiro, E. G. 2003. Effects of Galaxias maculatus on nutrient dynamics and phytoplankton biomass in a North Patagonian oligotrophic lake. - Environ. Biol. Fish. 68: 15-24.

Rosenzweig, M. L. 1971. Paradox of enrichment: destabilization of explotation ecosystems in ecological time. - Science 171: 385-387.

Schade, J. D., Kyle, M., Hobbie, S. E. et al. 2003. Stoichiometric tracking of soil nutrients by a desert insect herbivore. - Ecol. Lett. 6: 96-101.

Scheuerell, M. D., Schindler, D. E., Litt, A. H. et al. 2002. Environmental and algal forcing of Daphnia production dynamics. - Limnol. Oceanogr. 47: 1477-1485.

Schilling, C. H., Edwards, J. S., Letscher, D. et al. 2000. Combining pathway analysis with flux balance analysis for the comprehensive study of metabolic systems. - Biotechnol. Bioeng. 71: 286-306.

Shertzer, K. W., Ellner, S. P., Fussmann, G. F. et al. 2002. Predator-prey cycles in an aquatic microcosm: testing hypotheses of mechanism. - J. Anim. Ecol. 71: 802-816.

Sommer, U. 1992. Phosphorous-limited Daphnia-intraspecific facilitation instead of competition. - Limnol. Oceanogr. 37: 966-973.

Son, Y. and Gower, S. T. 1992. Nitrogen and phosphorus distribution for five plantation species in southwestern Wisconsin. - For. Ecol. Manage. 53: 175-193.

Stelzer, R. S. and Lamberti, G. A. 2002. Ecological stoichiometry in running waters: periphyton chemical composition and snail growth. - Ecology 83: 1039-1051.

Sterner, R. W. and Elser, J. J. 2002. Ecological stoichiometry: the biology of elements from molecules to the biosphere. - Princeton Univ. Press.

Thingstad, T. F. and Pengerud, B. 1985. Fate and effect of allochtonous organic material in aquatic microbial ecosystems. An analysis based on chemostat theory. - Mar. Ecol. Progr. Ser. 21: 47-62.
Throop, H. L. and Lerdau, M. T. 2004. Effects of nitrogen deposition on insect herbivory: implications for community and ecosystem processes. - Ecosystems 7: 109-133.

Tilman, D. 1982. Resource competition and community structure. - Princeton Univ. Press.

Tilman, D. 1985. The resource-ratio hypothesis of plant succession. - Am. Nat. 125: 827-852.

Tuljapurkar, S. and Caswell, H. (eds.). 1997. Structuredpopulation models in marine, terrestrial, and freshwater systems. - Chapman and Hall.

Urabe, J. and Sterner, R. W. 1996. Regulation of herbivore growth by the balance of light and nutrients. - Proc. Nat. Acad. Sci. USA 93: 8465-8469.

Urabe, J. and Sterner, R. W. 2001. Contrasting effects of different types of resource depletion on life-history traits in Daphnia. - Funct. Ecol. 15: 165-174.

Urabe, J., Elser, J. J., Kyle, M. et al. 2002a. Herbivorous animals can mitigate unfavourable ratios of energy and material supplies by enhancing nutrient recycling. - Ecol. Lett. 5: $177-185$

Urabe, J., Kyle, M., Makino, W. et al. 2002b. Reduced light increases herbivore production due to stoichiometric effects of light/nutrient balance. - Ecology 83: 619-627.

Villar-Argaiz, M. and Sterner, R. W. 2002. Life history bottlenecks in Diaptomus clavipes induced by phosphorus-limited algae. - Limnol. Oceanogr. 47: 1229-1233.

White, T. C. R. 1993. The inadequate environment: nitrogen and the abundance of animals. - Springer.

Ylioja, T., Roininen, H., Ayres, M. P. et al. 1999. Host-driven population dynamics in an herbivorous insect. - Proc. Nat. Acad. Sci. USA 96: 10735-10740.

Yoshida, T., Jones, L., Ellner, S. et al. 2003. Rapid evolution drives ecological dynamics in a predator-prey system. - Nature 424: 303-306.

Ågren, G. I. 2004. The C:N:P stoichiometry of autotrophstheory and observations. - Ecol. Lett. 7: 185-191. 